\title{
Zenker's diverticulum peroral endoscopic myotomy is effective in the case of an incipient Zenker's diverticulum
}

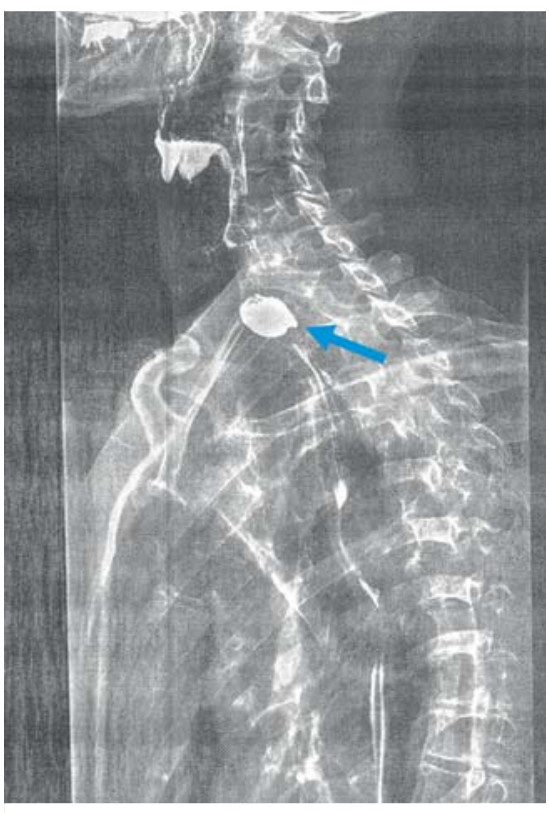

- Fig. 1 Barium swallow; black arrow indicates notch.

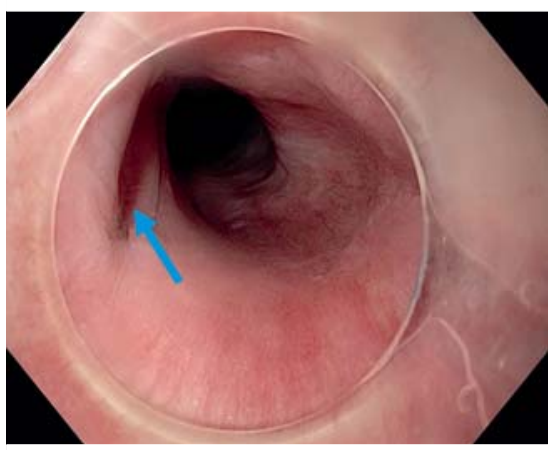

Fig. 2 Endoscopic aspect; black arrow shows the abnormal septum.

Zenker's diverticulum is a pulsion diverticulum developed in an area of weakness known as the Killian's triangle. Flexible endoscopic treatment of this condition was first introduced in 1982 and is now the first line of treatment [1]. This technique involves the division of the septum of the diverticulum, by incision with a cutting device, in order to achieve the cricopharyngeal myotomy, with the ob-

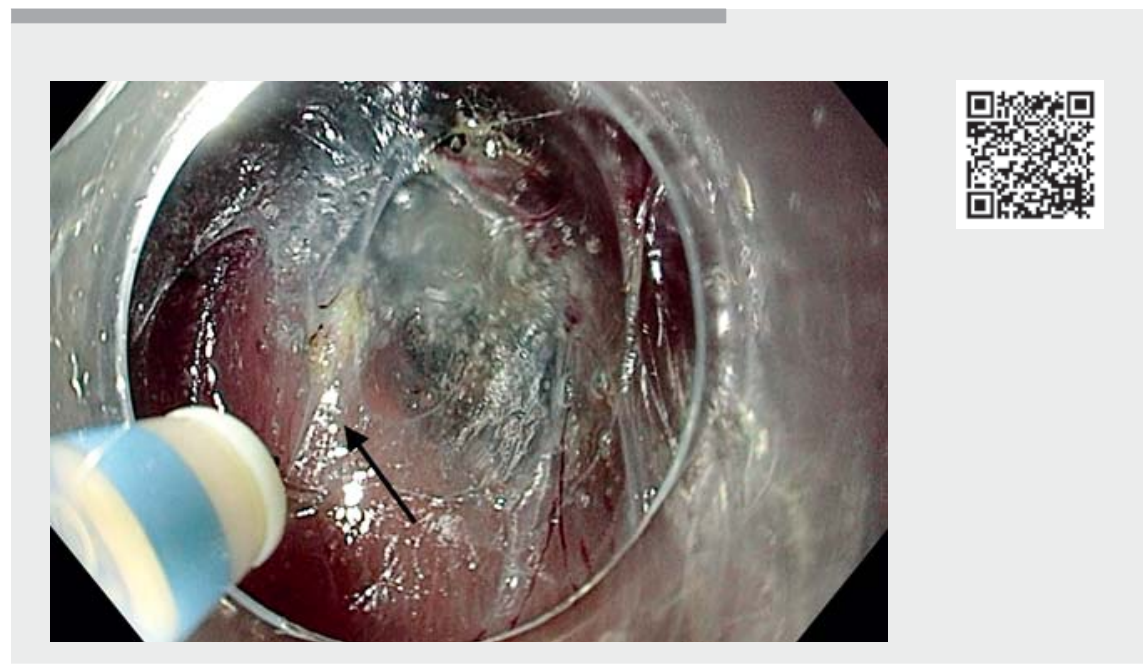

$\checkmark$ Video 1 Effective treatment of incipient Zenker's diverticulum using Zenker's diverticulum peroral endoscopic myotomy.

jective to reduce the size of the diverticulum and improve the symptoms (dysphagia, regurgitation, and respiratory symptoms).

$\mathrm{Li}$ and colleagues first described a novel endoscopic cricopharyngeal myotomy using the same principle as peroral endoscopic myotomy (POEM) for achalasia [2, 3]. This technique called Zenker's diverticulum peroral myotomy (ZPOEM) is aimed to reduce the risk of perforation, previously reported as high as 6.5\% [4]. We previously showed that zPOEM is also available as a rescue treatment after classical diverticulotomy [5].

We present here the case of a 61-year-old patient with a chronic history of proximal dysphagia. Under barium swallow we can see a notch (\$Fig. 1 ) that could be mistaken for a larger Zenker's diverticulum. In fact, the endoscopic examination showed a small proximal esophageal diverticulum (> Fig.2, > Video 1). We decided to perform zPOEM because our patient had severe chronic dysphagia that was affecting his quality of life. The mucosal incision was performed proximal to the septum followed by submucosal tunneling. An obvious cricopharyngeal septum was identified and completely sectioned. In the end, the mucosal incision was closed with endoclips. There were no complications. He reported complete symptom resolution 2 months later. Our case is particularly interesting because, even though the endoscopic examination shows a very small diverticulum, we can see an abnormally thick septum represented by the cricopharyngeal muscle, which needs to be sectioned in order to alleviate the patient's symptoms and prevent future enlargement of the diverticulum.

Endoscopy_UCTN_Code_TTT_1AO_2A]

Competing interests

The authors declare that they have no conflict of interest. 
Alexandru Lupu, Clara Yzet, Pierre Lafeuille Louis-Jean Masgnaux, Thomas Lambin, Jérôme Rivory, Mathieu Pioche

Gastroenterology and Endoscopy Unit, Edouard Herriot Hospital, Lyon, France

\section{Corresponding author}

\section{Alexandru Lupu, MD}

Gastroenterology and Endoscopy Unit, Edouard Herriot Hospital, 5 PI d'Arsonval, 29003 Lyon, France

alexandru.c.lupu@gmail.com

\section{References}

[1] Calavas L, Brenet E, Rivory J et al. Zenker diverticulum treatment: retrospective comparison of flexible endoscopic window technique and surgical approaches. Surg Endosc 2021; 35: 3744-3752
[2] Li QL, Chen WF, Zhang XC et al. Submucosal tunneling endoscopic septum division: a novel technique for treating Zenker's diverticulum. Gastroenterology 2016; 151: 1071-1074

[3] Inoue H, Minami H, Kobayashi Y et al. Peroral endoscopic myotomy (POEM) for esophageal achalasia. Endoscopy 2010; 42: 265271

[4] Ishaq S, Hassan C, Antonello A et al. Flexible endoscopic treatment for Zenker's diverticulum: a systematic review and meta-analysis Gastrointest Endosc 2016; 83: 1076 1089.e5

[5] Lambin T, Lafeuille P, Rivory J et al. When Z-POEM comes to the rescue of classical diverticulotomy and vice versa. Endoscopy 2021. doi:10.1055/a-1481-7728

\section{Bibliography}

Endoscopy 2022; 54: E700-E701

DOI 10.1055/a-1769-4203

ISSN 0013-726X

published online 28.2.2022

(c) 2022. Thieme. All rights reserved.

Georg Thieme Verlag KG, Rüdigerstraße 14,

70469 Stuttgart, Germany
ENDOSCOPY E-VIDEOS

https://eref.thieme.de/e-videos

口回 Endoscopy E-Videos is an open access online section, 回: reporting on interesting cases and new techniques in gastroenterological endoscopy. All papers include a high quality video and all contributions are freely accessible online. Processing charges apply (currently EUR 375), discounts and wavers acc. to HINARI are available.

This section has its own submission website at

https://mc.manuscriptcentral.com/e-videos 